\title{
Specificity trumps flexibility - location-based stable associations between Symbiodiniaceae genera and Platygyra verweyi (Scleractinia; Merulinidae)
}

\author{
Shashank Keshavmurthy ${ }^{1}$, Hwee-Sze Tee ${ }^{1,2}$, Kuo-Wei Kao ${ }^{1,3}$, Jih-Terng Wang ${ }^{\text {Corresp., } 4}$, Chaolun Allen Chen ${ }^{\text {Corresp. } 1,3,5}$ \\ 1 Biodiversity Research Center, Academia Sinica, Taipei, Taiwan \\ 2 Taiwan International Graduate Program, International Internship Program, Academia Sinica, Taipei, Taiwan \\ 3 Institute of Oceanography, National Taiwan University, Taipei, Taiwan \\ 4 Department of Oceanography, National Sun Yat-Sen University, Kaoshuing, Taiwan \\ 5 Department of Life Science, Tunghai University, Taichung, Taiwan \\ Corresponding Authors: Jih-Terng Wang, Chaolun Allen Chen \\ Email address: jtw@tajen.edu.tw, cac@gate.sinica.edu.tw
}

This study monitored symbiont communities bi-monthly in native coral cores used in a reciprocal transplantation of the coral Platygyra verweyiover two years (2014-2016) and samples of mother colonies from three locations with variable thermal regimes; our results show that associating with multiple Symbiodiniaceae genera (Cladocopium spp. and Durusdinium spp.) is not a prerequisite for symbiont shuffling. Platygyra verweyiassociates with certain Symbiodiniaceae genera based on location. Results of quantitative real-time PCR indicated small-scale temporal changes in Symbiodiniaceae genera compositions from 2014-2016; however, these changes were not enough to invoke shuffling or switching, despite degree heating weeks exceeding 6ㄷ-weeks in 2014 and 4ㅇ-weeks in 2015, which usually resulted in substantial coral bleaching. Microsatellite analysis of the $P$. verweyi host showed no genetic differences among the study locations. Our results suggest that $P$. verweyiundergoes long-term acclimatization and/or adaptation based on microgeographic and local environmental conditionsby altering its combinations of associated Symbiodiniaceae. Results also suggest that shuffling might not be as common a phenomenon as it has been given credit for; corals thrive through specific associations, and many corals could still be vulnerable to climate change-induced stress, despite being promiscuous or able to associate with rare and background Symbiodiniaceae genera. 
1 Specificity trumps flexibility-location-based stable associations between Symbiodiniaceae 2 genera and Platygyra verweyi (Scleractinia; Merulinidae)

3 Shashank Keshavmurthy ${ }^{1 \#}$, Hwee-Sze Tee ${ }^{1,2 \#}$, Kuo-Wei Kao ${ }^{1,3}$, Jih-Tern Wang ${ }^{\text {}}$, Chaolun Allen 4 Chen $1,3,5 \times$

5

$6 \quad{ }^{1}$ Biodiversity Research Center, Academia Sinica, Nangang, Taipei, Taiwan

7 2Taiwan International Graduate Program, International Internship Program, Academia Sinica, 8 Nangang, Taipei, Taiwan

9 Institute of Oceanography, National Taiwan University, Taipei, Taiwan

$10{ }^{4}$ Department of Oceanography, National Sun Yat-Sen University, Taiwan

11 5epartment of Life Science, Tunghai University, Taichung, Taiwan

12

13 \#: equal contribution

14 Corresponding authors: Chaolun Allen Chen, E-mail: cac@gate.sinica.edu.tw; 


\section{Abstract}

18 This study monitored symbiont communities bi-monthly in native coral cores used in a reciprocal transplantation of the coral Platygyra verweyi over two years (2014-2016) and samples of mother

20 colonies from three locations with variable thermal regimes; our results show that associating with 21 multiple Symbiodiniaceae genera (Cladocopium spp. and Durusdinium spp.) is not a prerequisite 22 for symbiont shuffling. Platygyra verweyi associates with certain Symbiodiniaceae genera based 23 on location. Results of quantitative real-time PCR indicated small-scale temporal changes in 24 Symbiodiniaceae genera compositions from 2014-2016; however, these changes were not enough 25 to invoke shuffling or switching, despite degree heating weeks exceeding $6^{\circ} \mathrm{C}$-weeks in 2014 and $264^{\circ} \mathrm{C}$-weeks in 2015, which usually resulted in substantial coral bleaching. Microsatellite analysis 27 of the $P$. verweyi host showed no genetic differences among the study locations. Our results 28 suggest that $P$. verweyi undergoes long-term acclimatization and/or adaptation based on 29 microgeographic and local environmental conditions by altering its combinations of associated 30 Symbiodiniaceae. Results also suggest that shuffling might not be as common a phenomenon as it 31 has been given credit for; corals thrive through specific associations, and many corals could still 32 be vulnerable to climate change-induced stress, despite being promiscuous or able to associate 33 with rare and background Symbiodiniaceae genera.

Key Words: Reciprocal transplantation, Thermal histories, Degree heating weeks, Symbiodiniaceae, Nuclear power plant 


\section{Background}

39 Corals in reefs around the world have been facing rapid declines in health over the past several decades due to increased and prolonged occurrences of climate change-induced seawater temperature anomalies, which often pass their threshold limits [1-3]. A common manifestation of

42 this stress is coral bleaching due to the breakdown of coral-Symbiodiniaceae associations [4]. Moreover, corals have the potential to acclimate to climate change-induced stressors-over a short period of time (single generation) — through phenotypic plasticity or associating with specific combinations of stress resistant Symbiodiniaceae genera through natural selection; this may be the overriding determinant of their survival [5]. However, a beneficial association between a coral host and Symbiodiniaceae is a complex and holistic process that depends on whether the relationship that the coral host has with the Symbiodiniaceae genera is specific or flexible [6-8]. Corals are known to associate with a wide range of Symbiodiniaceae genera. There are nine genera of Symbiodiniaceae, and each has its own characteristic traits that help its coral host survive in a wide range of environmental niches [9]. Studies have shown that symbiosis between coral hosts and different Symbiodiniaceae genera contributes to the divergence in coral thermal tolerance under different environmental conditions [7,10]. For instance, species of Durusdinium are considered to be heat tolerant [6,11-13],; most species Cladocopium are stress sensitive but several are relatively stress tolerant (e.g. in- hospite Cladocopium C15, Cladocopium thermophilum) $[14,15]$. Durusdinium-associated corals are also known to inhabit reef environments that experience large fluctuations in surface seawater temperature $[7,16,17]$ and be more resilient to heat-treatment experiments [18].

One widely-known mechanism that helps some corals acclimate to stressful environments is shuffling and/or switching their associated Symbiodiniaceae genera [19-25]. It has been proposed that coral hosts adjust to increasing seawater temperatures using switching-which involves existing Symbiodinium being expelled and replaced by novel Symbiodinium from the environment-and shuffling between stress-sensitive (generally Cladocopium sp.) and stressresistant types (generally Durusdinium sp.) in the existing symbiont communities [19, 20, 26, 27]. Shuffling between Symbiodiniaceae genera has been found to benefit some coral species $[11,12]$ because increasing the abundance of stress-tolerant Symbiodiniaceae genera in a multi-symbiont association helps corals withstand above-threshold seawater temperature anomalies [16-18]. A transition from thermally sensitive to tolerant dominant symbionts can increase the likelihood that 
69 corals survive thermally-induced bleaching [28]. However, a later study [29] argued that not all 70 corals can change their symbionts, because the mechanism of shuffling requires that a coral species 71 hosts multiple Symbiodiniaceae genera (at least one stress tolerant and one stress resistant). Some 72 coral species have the ability to fluctuate between Symbiodiniaceae genera on a temporal scale 73 (e.g. [30]). The occurrence of multiple Symbiodiniaceae genera at low densities might lead to 74 either shuffling or switching to beneficial Symbiodiniaceae genera over time [30]. In some cases, 75 the coral host may revert back to its original composition of either a single dominant 76 Symbiodiniaceae species or multiple species/genera (see [31]). However, there are also many cases 77 in which the host maintains stable symbiosis with a particular Symbiodiniaceae genus, irrespective 78 of environmental perturbations (see [31,32]). This acclimatization mechanism, although limited, 79 may help corals survive the effects of ocean warming in the near future $[20,33]$.

In order to assess whether associating with multiple Symbiodiniaceae is in itself enough for shuffling to happen, we analysed coral samples collected over time from locations with different thermal regimes to determine how location influences corals' abilities to shuffle and subsequently survive. Nanwan, Kenting National Park, Taiwan is a reef site located southwest of the third Nuclear Power Plant Outlet (NPP-OL) that has been affected by the continuous discharge of thermal effluent flowing directly into the existing coral community as a result of the near-shore current [34] since the power plant opened in 1984. NPP-OL has seawater temperatures similar to those predicted for oceans around the world by 2050 [1], making it an ideal location to conduct studies related to the effects of climate change. Nuclear power plant -OL has significantly different community compositions and settlement patterns compared to other sites such as the Nuclear Power Plant Inlet (NPP-IL) [35], suggesting that the thermal effluent has had areat impact on its benthic invertebrate and fish communities. Corals present at NPP-OL have also experienced several bleaching events over time (see [36,37]). The coral communities in the shallow water $(3$ m) are dominated by thermally tolerant symbiont types [30,38,39]. The increasing prevalence of stress-tolerant Durusdinium sp. at reef sites closer to NPP-OL reflects the consequences of longterm thermal effects; this prevalence also makes NPP-OL an ideal site to study holobiont dynamics under thermal stress, although other physical differences (temperature fluctuations, upwelling, and internal waves; see [40]) between NPP-OL and other sites could also be involved [30,38,39,41,42]. 
98 In this study, we collected data from in situ reciprocal transplant experiments (RTE) on nubbins 99 of P. verweyi collected from NPP-OL, NPP-IL, and Wanlitung (WLT) in Kenting National Park 100 (KNP) between 2014-2016 (see [43]). Using the samples from each location of origin (tagged 101 mother colonies and native cores used in the transplant experiment), we tested whether corals in 102 their native environments will undergo shuffling over time and associate with favourable 103 Symbiodiniaceae genera.

104 


\section{Methods}

106 Samples used in the experiment were collected with permission from the Kenting National Park

107 headquarters (permit numbers 1040008112 and 1040002080).

109 Study area and coral species

110 All experiments and sampling were carried out at three locations: Nuclear Power Plant Outlet 111 (NPP-OL), Nuclear Power Plant Inlet (NPP-IL), and Wanlitung (WLT) in Nanwan, southern

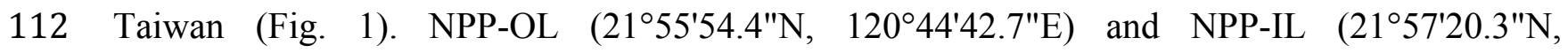
$\left.113120^{\circ} 45^{\prime} 14.2^{\prime \prime} \mathrm{E}\right)$ are located within Nanwan in the Kenting National Park (KNP), Taiwan, and WLT $114\left(21^{\circ} 59^{\prime} 41.0^{\prime \prime} \mathrm{N} 120^{\circ} 42^{\prime} 19.6^{\prime \prime} \mathrm{E}\right)$ is located on the west coast of KNP, approximately $12 \mathrm{~km}$ from the 115 nuclear power plant area. Due to the tidally-induced upwelling in Nanwan [41], the maximum 116 daily seawater temperature fluctuation at NPP-OL and NPP-IL can exceed $8^{\circ} \mathrm{C}$ in the summer 117 season. In this study, NPP-IL and WLT were both included to assess the potential role of thermal 118 variability on $P$. verweyi facing prolonged thermal stress. The massive coral species $P$. verweyi 119 generally occurs in shallow water (2-4 m) and was found to associate with the Symbiodiniaceae 120 genera Cladocopium sp. and/or Durusdinium sp. in KNP [38].

121

\section{Coral samples}

123 Two types of samples were used in the experiment: the "mother colonies" were the original 124 colonies (from the 2014-2016 transplantation experiment), and the "native cores" were samples 125 cut from a mother colony and kept at the same location.

126 Tagged mother colonies at each location (five from NPP-IL in 2014, eight each from NPP-OL and 127 WLT from 2014 to 2016) were sampled approximately every two months throughout the 128 experimental period. During each sampling, a piece (2 cm diameter core) of coral was cut and 129 fixed in 95\% Ethanol for DNA extraction and qPCR analysis.

130 Samples were taken from the coral cores in the racks used in the transplantation experiment (see 131 [43] for detailed explanation of the transplantation experiment). All samples were taken from the 132 set of control racks installed at each location from the reciprocal transplant experiment, and hence 133 referred to as "native cores". Five native cores (one from each colony) from each rack in 2014 (at 134 all three sites) and one piece ( $2 \mathrm{~cm}$ in diameter) from each of the 30 cores in 2015 (from the racks 
135 at NPP-OL and WLT) were sampled at each location. Sampling for the 2014 set was carried out

136 in April and September of 2014 and January, March, May, July, September, and November of

137 2015. Sampling for the 2015 set was carried out in April, September, and November of 2015 and

138 January and April of 2016. All samples were fixed in 95\% Ethanol for DNA extraction and qPCR

139 analysis.

\section{Seawater temperature}

141 The seawater temperature was recorded in situ at 30-minute intervals using data loggers (HOBO;

142 Pendant ${ }^{\mathrm{TM}}$, USA) deployed underwater near the transplant racks (1-2 m) at each study site. The

143 raw temperature data were transformed into Degree Heating Weeks (DHW) $[44,45]$ to assess both

144 the intensity and duration of the thermal stress for each experiment group. Although this indicator

145 is typically used to monitor large-scale bleaching, it was also used in another study to assess the

146 cumulative thermal stress on heat-treated corals, but daily [46]. DHW was calculated as follows.

147 First, the weekly mean temperature for each study site was calculated from raw temperature data.

148 Second, the maximum of the monthly mean temperatures $\left(\mathrm{MMM}\right.$; NPP-OL $=29.63^{\circ} \mathrm{C}$; WLT $=$

$\left.14929.28^{\circ} \mathrm{C} ; \mathrm{NPP}-\mathrm{IL}=28.37^{\circ} \mathrm{C}\right)$ was obtained from data loggers (HOBO; Pendant ${ }^{\mathrm{TM}}$, USA) deployed

150 at each study location. Finally, the weekly mean temperature was subtracted from MMM to

151 determine temperature anomalies; only temperatures at least $1.0^{\circ} \mathrm{C}$ above the MMM within the

152 previous 12 weeks were considered anomalies and summed to obtain the DHW. The conceptual

153 calculation equation is listed below

154

$$
D H W_{T W O}=\sum\left[\left(T_{N P P-O L}-M M M_{W L T}\right) \geq 1^{\circ} \mathrm{C}\right]
$$

155 where $\mathrm{T}_{\mathrm{NPP}-\mathrm{OL}}$ is the weekly mean temperature at NPP-OL, MMM $\mathrm{WLT}_{\mathrm{T}}$ is the MMM of WLT, etc.

156 The projections of DHW in Nanwan were obtained from [33] using a $1^{\circ} \times 1^{\circ}$ resolution grid of reef 157 cells located in southern Taiwan.

158

159 DNA extraction

160 DNA extraction was carried out using a salting-out method modified from [47]. Coral tissue was

161 lysed overnight in a 2-mL Eppendorf tube with $200 \mu \mathrm{L}$ of lysis buffer [0.25 M Tris, 0.05 M EDTA 162 at $\mathrm{pH} 8.0,2 \%$ sodium dodecylsulfate (SDS) and $0.1 \mathrm{M} \mathrm{NaCl}]$ and $10 \mu \mathrm{L}$ of $10 \mathrm{mg} / \mathrm{mL}$ proteinase $163 \mathrm{E}$ at $55^{\circ} \mathrm{C}$ in a water bath. $\mathrm{NaCl}(210 \mu \mathrm{L}$ at $7 \mathrm{M})$ was added to the lysed tissue in the tube, and the 
164 sample was mixed by carefully inverting the tube. The solution was then transferred to a 2-mL 165 collection tube containing a DNA spin column (Viogene, USA) and centrifuged at $8000 \mathrm{rpm}$ for 1 $166 \mathrm{~min}$. The lysate was washed twice with $500 \mu \mathrm{L}$ of ethanol $(70 \%)$ by centrifuging at $8000 \mathrm{rpm}$ for

$1671 \mathrm{~min}$ at each step, with an additional centrifugation step at $8000 \mathrm{rpm}$ for 3 min to dry the spin 168 column. The column was dried further at $37^{\circ} \mathrm{C}$ for $15 \mathrm{~min}$, then the DNA was eluted with $50 \mu \mathrm{L}$ 169 of preheated $\left(65^{\circ} \mathrm{C}\right) 1 \mathrm{X}$ TE buffer, with a final centrifugation at $15000 \mathrm{~g}$ for $3 \mathrm{~min}$. The quality of 170 genomic DNA was checked using a 1\% agarose gel. The concentrations of genomic DNA were 171 determined using NanoDrop 2000 (Thermal Scientific, USA).

172

173 The copy numbers of Cladocopium sp. and Durusdinium sp. in P. verweyi samples were 174 determined under a LightCycler® 480 Instrument II (Roche, Switzerland) using a protocol 175 modified from [48]. Each $10 \mu \mathrm{L}$ qPCR reaction consisted of $5 \mu \mathrm{L}$ 1x SYBR Fast Master Mix, 0.5 $176 \mu \mathrm{L}$ UF primer $(2 \mathrm{nM} / \mu \mathrm{L}), 0.5 \mu \mathrm{L}$ CR or DR primer $(2 \mathrm{nM} / \mu \mathrm{L}), 7.5 \mu \mathrm{L} \mathrm{ddH}_{2} \mathrm{O}$, and $2.5 \mu \mathrm{L}$ DNA 177 templates (equal to $1 \mathrm{ng}$ of genomic DNA). The following primer sets were used: ITS1 clade C178 specific reverse primer (CR) 5-AAGCATCCCTCACAGCCAAA-3, clade D-specific reverse 179 180

181

182

183

184

185

186

188

189

190

191

192

193 primer (DR) 5-CACCGTAGTGGTTCACGTGTAATAG-3, and universal forward primer (UF) 5AAGGAGAAGTCGTAACAAGGTTTCC-3 [12]. Each sample was run in triplicate (technical replicates), as was a no-template control (NTC) with $\mathrm{ddH}_{2} \mathrm{O}$. Plasmid standard curves were run in duplicate with $P$. verweyi samples to quantify the copy numbers of each symbiont. Plasmid standard curves were generated using PCR products from Cladocopium sp. and Durusdinium sp., which were ligated into $\mathrm{pGem}^{\circledR}$-T Easy vectors (Promega, USA), transformed, and amplified using E. coli. Copy numbers of final products were calculated by first quantifying the concentration of plasmid DNA through NanoDrop 2000 (Thermal Scientific, USA), then dividing by the mass of the plasmid [mass of each plasmid copy $=3015 \mathrm{bp}$ (vector) $+100 \mathrm{bp}$ (inserted PCR product) $\mathrm{x}$ $1.096 \mathrm{e}^{-21} \mathrm{~g} / \mathrm{bp}=3.4 \times 10^{-18} \mathrm{~g}$ ], and finally multiplying by the plasmid DNA template volume $(2.5$ $\mu \mathrm{L})$ in each reaction. Serial dilutions of $1: 10$ from $3 \times 10^{6}$ and 30 copies of the plasmid standard containing Cladocopium sp. and Durusdinium sp. sequences, respectively, were generated in the end. The qPCR cycling settings were: 40 two-step cycles of $15 \mathrm{~s}$ at $95^{\circ} \mathrm{C}$ and $1 \mathrm{~min}$ at $60^{\circ} \mathrm{C}$. Melting curves were generated by starting at $60^{\circ} \mathrm{C}$ and increasing the temperature with a ramp speed of $0.11^{\circ} \mathrm{C} / \mathrm{s}$ until it reached $95^{\circ} \mathrm{C}$. Fluorescence data were collected after each annealing step, and five 
194 readings were collected every second during the melting curve analysis. Crossing points $(\mathrm{Cp})$ were 195 determined by Light Cycler 480 software version 1.5 (Roche, Switzerland) using the second 196 derivative method, which represents the cycles with the maximum number of fluorescence signals 197 in each sample [49]. Samples with $\mathrm{Cp}$ values that varied from the other two technical replicates by 1981 were excluded from analysis. Samples were re-run if all $\mathrm{Cp}$ values of technical replicates varied 199 from one another by 1 . Since high variation occurred in Cp values (varied more than 1) within 200 technical replicates of each sample when $\mathrm{Cp}>34$, the cut-off cycle was set to 34 to avoid false 201 positives caused by the formation of non-specific fluorescence. Average copy numbers of 202 symbiont clades C and D were obtained individually, and the formula for determining relative 203 symbiont abundance in this study is listed below, following a correction suggested by [48]:

204 (Clade D copy numbers / 3) / [(Clade D copy numbers / 3) + Clade C copy numbers ]

205

206

Population genetics analysis of $\mathrm{P}$. verweyi

207 To demonstrate the presence of a genetic structure in P. verweyi at NPP-OL and WLT, eight 208 polymorphic microsatellite loci were used to examine $30 \mathrm{P}$. verweyi colonies (including 209 transplanted colonies) found within two transplanted sites. Three published microsatellite tetramer 210 markers developed from P. sinensis [50] and P. daedalea [51] were used. Another five 211 microsatellite dimer markers specific to $P$. verweyi were developed by Next Generation 212 Sequencing approaches [52]. Eight microsatellite markers were amplified following the effective 213 universal fluorescent labeling method [53]. Amplifications performed using $25 \mu \mathrm{L}$ reactions 214 contained $10 \mathrm{ng}$ of DNA template, 1X of VeraSeq Buffer II (Qiagen Beverly, USA), 0.5U of 215 VeraSeq 2.0 high-fidelity DNA polymerase (Qiagen Beverly, USA), $0.2 \mathrm{mM}$ of dNTP mix, 0.08 $216 \mu \mathrm{M}$ of specific forward primer-attached M13 (-21) tail (5' - TGT AAA ACG ACG GCC AGT -3') 217 (18 bp), $0.2 \mu \mathrm{M}$ of specific reverse primer, and $0.2 \mu \mathrm{M}$ TAMRA-labelled universal M13 (-21) 218 primer (5' - TGT AAA ACG ACG GCC AGT -3') [53]. The PCR conditions were: 1 cycle at $98^{\circ} \mathrm{C}$ 219 for $30 \mathrm{~s} ; 25$ cycles of $98^{\circ} \mathrm{C}$ for $10 \mathrm{~s}$, specific primer annealing temperature (Table 1) for $30 \mathrm{~s}$, and $22072^{\circ} \mathrm{C}$ for $30 \mathrm{~s}$; followed by 10 cycles of fluorescent-labelled M13 amplification: $98^{\circ} \mathrm{C}$ for $10 \mathrm{~s}$, $22153^{\circ} \mathrm{C}$ for $30 \mathrm{~s}, 72^{\circ} \mathrm{C}$ for $30 \mathrm{~s}$; and a final elongation of $10 \mathrm{~min}$ at $72^{\circ} \mathrm{C}$. For microsatellite 222 genotyping, samples were electrophoresed on 5\% urea denaturing polyacrylamide gels using the 223 Gel-Scan $3000^{\mathrm{TM}}$ real-time DNA fragment analysis gel Electrophoresis System (Corbett Robotics, 224 Australia). Allele size was detected by the software Gene Profiler 4.05 (Scanalytics) with the 
225 internal lane size standard (GeneScan ${ }^{\mathrm{TM}}-350 \mathrm{TAMRA}^{\mathrm{TM}}$, Applied Biosystems). Characteristics of

226 microsatellite loci - such as number of alleles and mean observed and expected heterozygosities-

227 were calculated using GenAlEx v.6.502 [54]. Genepop was used on the web to test for linkage

228 disequilibrium and significant departure from Hardy-Weinberg equilibrium (HWE). None of the

229 loci showed HWE deviation or linkage disequilibrium after Bonferroni correction [55]. Population

230 differentiation was inferred using ARLEQUIN v3.5 [56]. Inference population genetic structure

231 was estimated using a Bayesian clustering approach implemented in STRUCTURE v.2.3.4 [57].

232 The admixture model and allele frequency correlation were used. Values of number of genetic

233 clusters (K) from 1 to 2 were tested by running three replicate simulations per $\mathrm{K}$ with 1,000,000

234 Markov chain Monte Carlo repetitions and 100,000 burn-in iterations.

\section{Statistical analysis}

236 All statistical analyses in this study were performed in R version 3.1.1. [58]. Differences in daily 237 mean seawater temperatures and daily seawater temperature fluctuations between sites were tested 238 using Kruskal-Wallis test followed by Dunn's post hoc test with Bonferroni adjusted p-values. 


\section{Results}

\section{Seawater temperature}

242 Weekly average seawater temperatures were plotted from the data collected by data loggers from 2432014 and 2106. Both monthly and daily average seawater temperatures at NPP-OL were 244 significantly higher $\left(2.0-3.0^{\circ} \mathrm{C}\right)$ than at adjacent locations (Fig. 2A). In 2014, the average summer 245 (June to August) daily seawater temperature at NPP-OL $\left(30.11 \pm 1.07 \mathrm{SD}^{\circ} \mathrm{C}\right)$ was different from 246 those at WLT $\left(29.59 \pm 0.67 \mathrm{SD}^{\circ} \mathrm{C}\right.$; Dunn's post hoc test, $\left.\mathrm{p}<0.001\right)$ and NPP-IL $(28.61 \pm 0.96 \mathrm{SD}$ $\left.247{ }^{\circ} \mathrm{C} ; \mathrm{p}<0.001\right)$. In 2015, the average summer daily seawater temperature at NPP-OL $(29.77 \pm 1.12$ $\left.248 \mathrm{SD}^{\circ} \mathrm{C}\right)$ was different from that at WLT $\left(29.52 \pm 0.52 \mathrm{SD}^{\circ} \mathrm{C}\right.$; Wilcoxon rank sum test, $\mathrm{W}=5097$, $249 \mathrm{p}<0.05)$. The daily seawater temperature fluctuation at NPP-OL $\left(2.38 \pm 1.04 \mathrm{SD}^{\circ} \mathrm{C}\right)$ was different 250 from that at $\operatorname{WLT}\left(1.57 \pm 0.70 \mathrm{SD}^{\circ} \mathrm{C}\right.$ ) (Wilcoxon rank sum test, $\left.\mathrm{W}=655557, \mathrm{p}<0.001\right)$. The heating 251 event $\left(\geq 30^{\circ} \mathrm{C}\right)$ at NPP-OL occurred for a longer time each day than at WLT.

252 The daily seawater temperature fluctuation at NPP-OL $\left(2.23 \pm 1.00 \mathrm{SD}{ }^{\circ} \mathrm{C}\right)$ was different from 253 those at WLT $\left(1.53 \pm 0.58 \mathrm{SD}^{\circ} \mathrm{C} ; \mathrm{p}<0.001\right)$ and NPP-IL $\left(1.80 \pm 1.30 \mathrm{SD}{ }^{\circ} \mathrm{C} ; \mathrm{p}<0.001\right)$, while the 254 fluctuations did not vary between WLT and NPP-IL $(\mathrm{p}=1.000)$. During the summer, however, the 255 daily seawater temperature fluctuation at both NPP-OL and NPP-IL was more than $7^{\circ} \mathrm{C}$ (maximum $2569.12^{\circ} \mathrm{C}$ at NPP-OL and $7.19^{\circ} \mathrm{C}$ at NPP-IL). The daily heating event $\left(\geq 30^{\circ} \mathrm{C}\right)$ occurred for the 257 longest time at NPP-OL.

258 In 2014, repeated seawater temperature anomalies (the weekly mean seawater temperature 259 exceeding the bleaching threshold) occurring at NPP-OL during the summer, resulting in a DHW 260 of $6.4^{\circ} \mathrm{C}$-weeks, while those at NPP-IL and WLT were 2.4 and $1.0^{\circ} \mathrm{C}$-weeks respectively (Fig 2B). 261 DHW greater than $4.0^{\circ} \mathrm{C}$-weeks results in a NOAA Alert Level 1, meaning that bleaching is likely. 262 The DHWs started to decrease gradually in the fall. In 2015, the DHWs for both NPP-OL and 263 WLT were below the threshold limit of $4.0^{\circ} \mathrm{C}$-weeks-3.8 and 1.0 for NPP-OL and WLT, 264 respectively.

265

266 Temporal variation in Symbiodiniaceae genera associated with $\mathrm{P}$. verweyi at NPP-OL 
267 The results of the real-time qPCR analysis of the samples from the 2014 experiment (Fig. 3A) 268 indicated that, until January 2015, the symbiont communities in the native cores of NPP-OL were 269 dominated by Durusdinium spp. In March 2015, the relative proportions of symbionts changed: 270 Cladocopium spp. were present at various percentages (range: 1-21\%; mean: 6\%; Fig. 3A), and 271 Durusdinium spp. accounted for the rest. Symbiont dynamics in the core with $21 \%$ Cladocopium 272 spp. did continue to fluctuate (13\% in May; $18 \%$ in July and September; Fig. 4). However, this 273 core was dead by November 2015. All remaining cores survived, fluctuating between 1-5\% (mean: $2742 \%)$ Cladocopium spp. for the entire experiment.

275 In the 2015 experiment (Fig. 3B), the symbiont community in the native core samples from NPP276 OL were dominated by Durusdinium spp. However, qPCR suggested that the cores in the samples 277 from April 2016 were associated with Cladocopium spp. in addition to the already present 278 Durusdinium spp. Previously undetected levels of Cladocopium spp. increased enough to be 279 detected by qPCR. Cores were found to contain 3-61\% (mean: 22.6\%) Cladocopium spp. in April 2802016.

281 Bimonthly sampling of the mother colonies revealed that $P$. verweyi was specific with respect to 282 which Symbiodiniaceae genera it associated with (Fig. 4). Colonies sampled from NPP-OL 283 showed changes in associated Symbiodiniaceae, meaning that none of the 30 colonies analysed 284 were associated with $100 \%$ Durusdinium spp. throughout the entire study period. However, the 285 fluctuation between Durusdinium spp. and Cladocopium spp. was not large. Colonies were found 286 to host $91-100 \%$ Durusdinium spp. (seven of the nine colonies) - one colony hosted 50 and $80 \%$ 287 at two sampling times - with the exception of one colony, which associated with 72 and $99 \%$ 288 Durusdinium spp. in November 2014 and January 2015, respectively. However, this colony 289 changed its relative proportion of symbionts to 100\% Cladocopium spp. in March 2015, and then 290 reverted to $97 \%$ Durusdinium spp. in May 2015. This was the only colony that had a large 291 fluctuation in associated Symbiodiniaceae between the two Symbiodiniaceae genera.

293 Temporal variation in Symbiodiniaceae genera associated with P. verweyi at WLT 
294 In the 2014 experiment samples from WLT, a predominance of Cladocopium spp. was observed 295 in the majority of the cores (Fig. 3A), with the exceptions of two cores found dead from March 2962015 onwards and one colony that reverted to Durusdinium spp. (83\%).

297 In 2015, cores from WLT were mainly associated with Cladocopium spp., ranging from 5-99\% 298 (mean: 31\%) (Fig. 3B). Five of the 30 cores were associated with Durusdinium spp. throughout 299 the experimental period. However, in November 2015, 12 of the 30 cores were associated with 300 Durusdinium spp. (range: 1-87\%; mean: 32\%). Three cores at WLT that were mainly associated 301 with Cladocopium spp. were dead by the end of the sampling period in April 2016 (Fig. 3B).

302 In the case of the WLT bimonthly analysis of the samples from the mother colonies, seven of the 303 eight colonies analysed were associated only with Cladocopium spp., except for one colony, which 304 also associated with Durusdinium spp. (2\% in November, 2014; 1\% in July, 2015; and 2\% in April, 305 2016) in addition to Cladocopium spp. (Fig. 4).

306

307 Temporal variation in Symbiodiniaceae genera associated with P. verweyi at NPP-IL

308 In 2014, all the cores at NPP-IL were found to be predominantly associated with Cladocopium 309 spp. throughout the experimental period. None of the cores were associated with Durusdinium spp. 310 (Fig. 3A).

311 With respect to the bimonthly analysis of the samples collected from the mother colonies, again 312 all the samples were predominantly associated with Cladocopium spp. throughout the sampling 313 period. However, some colonies did show the presence of Durusdinium spp. (1\% in March, May, 314 and November; 29\% in October, 2015; Fig. 4).

Microsatellite analysis of host samples from NPP-OL and WLT

317 Microsatellite analysis revealed that a total $60 \mathrm{P}$. verweyi colonies (30 each from NPP-OL and 318 WLT) exhibited six to 16 alleles per locus for all eight microsatellite loci, with a mean expected 319 heterozygosity of $0.756 \pm 0.122$ (Table 1 ). Average gene diversity of $P$. verweyi at NPP-OL across 320 eight loci was $0.608 \pm 0.393$; the average for populations at WLT was $0.657 \pm 0.460$. The pairwise 321 genetic differentiation $\mathrm{F}_{\mathrm{st}}$ value between the two sites was -0.00814 , and the $\mathrm{p}$-value showed no 
322 significant difference. The genetic structure analysis by Bayesian clustering between NPP-OL and 323 WLT also showed no significant differences and no genetic isolation between the two locations 324 (Fig. 5). 


\section{Discussion}

327 The present study shows spatial variation but specificity in the dominant Symbiodiniaceae genera 328 in the coral $P$. verweyi, and this may be related to local thermal histories. What was seen in $P$. 329 verweyi is an almost stable association with a dominant Symbiodiniaceae genus at each sampling 330 time from 2014 to 2016. A fluctuation was observed between Symbiodiniaceae in native cores 331 and/or mother colonies, but this was not a general phenomenon. There was a certain level of 332 temporal and spatial fluctuation in the native coral cores and tagged mother colonies. For example, 333 in the 2014 experiment, some cores at NPP-OL (nubbins here are associated with Durusdinium 334 spp.) did acquire low percentages of Cladocopium spp. (in March 2015) relative to the already 335 present Durusdinium spp. (Fig. 3A). A similar fluctuation was seen in one core from WLT, which 336 was found to have acquired up to $83 \%$ Durusdinium spp. However, none of the cores at NPP-IL 337 showed any fluctuation (Fig. 3A). A similar pattern was observed in the tagged mother colonies, 338 with low levels of fluctuation and Symbiodiniaceae genera acquisition (Fig. 4).

339 Considering the differences in seawater temperature regimes among the three locations (Fig. 2A), 340 this study assumed that native cores and mother colonies would show different levels of 341 Symbiodiniaceae genera shuffling through time. However, the results showed that one

342 Symbiodiniaceae genus was always dominant in each sample (Fig. 3, 4). For example, samples at 343 NPP-OL were always dominated by Durusdinium spp. Such preference could be because corals at 344 NPP-OL are exposed to long-term seawater temperature stress at shallow depths (1-5 m) and hence 345 are naturally acclimatized to an association with Durusdinium spp.

346 Association with a particular dominant symbiont could help $P$. verweyi dominate shallows at 347 various locations in KNP. During the experiment and sampling periods (2014-2016), there was 348 one major bleaching event (2014) and several typhoons (2015). Irrespective of the type of 349 symbiont $P$. verweyi associated with, none of the corals experienced any clear bleaching350 although some degree of paling of the tissue was observed. Increased seawater temperatures in 3512014 resulted in DHWs of 6, 2.5, and $1^{\circ} \mathrm{C}$-weeks at NPP-OL, WLT, and NPP-IL, respectively [43]. 352 DHW in 2015, however, was below $4^{\circ} \mathrm{C}$-weeks in both NPP-OL and WLT (Fig. 2B). The lower 353 DHW values in 2015 could be attributed to the typhoons that occurred that year: the southern coast 354 of Taiwan was hit by three typhoons in the summer, July - September 2015, resulting in the 355 seawater temperature cooling. Such intense changes in seawater temperature conditions might 356 have resulted in corresponding fluctuations in associated Symbiodiniaceae genera in some cores 
357 or tagged mother colonies (Fig. 3, 4). Temperature anomalies found in 2014, with high DHWs, 358 were not enough to yield any pronounced shuffling or switching in this coral.

359 Our observations beg the following questions: how common is shuffling in corals that can 360 associate with two different symbionts, and does flexibility in symbiont associations via shuffling 361 aid corals under stress? Studies have pointed out that corals often associate with two or more 362 symbionts, with one being dominant and others present at low proportions $(<5 \%$, background 363 symbiont) [8]. Therefore, corals have potential to shuffle by regulating their proportions of 364 background symbionts when faced with unfavourable conditions. In this study, we detected 365 symbionts at abundances as low <1\%; however, such low concentrations might not be a 366 prerequisite for shuffling or even switching. Also, the recent use of NGS amplicon sequencing has 367 uncovered a rare biosphere with the potential to shuffle and/or switch between different 368 Symbiodiniaceae genera. For example, [31] investigated the Symbiodiniaceae rare biosphere in 369 two Pocilloporid species from Lord Howe Island in the Great Barrier Reef over two years. Their 370 results showed that, following two consecutive bleaching events, the species shuffled and became 371 associated with new Symbiodiniaceae genera (most $<1 \%$ of the relative abundance, with one 372 resistant type reaching $33 \%$ of the relative abundance).

373 On the other hand, [59] suggested that a pre-stress Symbiodiniaceae (D:C) ratio of $<0.003$ limits 374 the ability of corals to survive bleaching after shuffling. And another study [60] showed that 375 variation in the presence and abundances of background or low percentages of symbionts in corals 376 is not necessarily related to shuffling, and may have little or no importance in coral physiology. 377 Future studies need to examine the physiological role of those rare biospheres in terms of 378 supporting corals' responses to stress.

379 It may be argued that specificity to a particular Symbiodiniaceae genus depends on the host. We 380 performed genetic analyses on the host using mitochondrial and nuclear markers in a previous 381 study [38] and microsatellite markers in this study. The results showed no genetic difference in the 382 host between locations. This suggests that other factors influence the type of association we see in 383 this coral, including possible local and microgeographic adaptations to seawater temperature. It 384 may be that using more advanced techniques would help uncover prevalent genetic differences 385 between hosts from two locations in KNP, as was shown in a recent study-[61], which showed a 386 clear genetic difference in $P$. daedalea-associated Symbiodiniaceae between Oman and Abu Dhabi 387 in the Persian Gulf, and hence demonstrated a difference in their eco-physiological behaviour. 
388 Both macro- and micro-environmental differences between locations could dictate 389 Symbiodiniaceae genera associations in $P$. verweyi. For example, typhoons and upwelling or 390 fluctuating temperatures in shallow reef areas could raise the thermal tolerance of coral, as could 391 the influence of fluctuating environmental factors such as tidal exposure [62]. Although we 392 demonstrated that Symbiodiniaceae mediate $P$. verweyi acclimatization, we cannot rule out the 393 possibility that mutations to the host itself and natural selection lie behind this species' ability to 394 adapt to a particular condition. The effect of micro-environment might also explain the difference 395 seen in the Symbiodiniaceae genera association between the native cores and mother colonies. 396 Specificity towards a particular Symbiodiniaceae genus was more apparent in the mother colonies 397 (Fig. 4). Native cores, due to their small size and hence propensity toward stress, showed more 398 flexibility in their associated Symbiodiniaceae genera (Fig. 3 A, B) [also see the results in 43].

399 We hypothesize that combinations of $P$. verveyi and Symbiodiniaceae genera tend to be specific 400 due to the differences in thermal histories, temperature variations, and hosts favouring one 401 dominant symbiont rather than shuffling. This could have a negative impact on coral exposed to 402 above-threshold thermal anomalies. For example, [43] observed that, when P. verveyi nubbins 403 were reciprocally transplanted between NPP-OL and WLT, those from WLT that were associated 404 with Cladocopium spp. did not tolerate long-term changes in temperature levels or daily 405 fluctuations. The transplanted nubbins did not survive, even after shuffling. In contrast, nubbins at 406 NPP-OL survived and actually fared well in the more stable and lower-temperature environment 407 of WLT. In fact, they also showed an increase in growth over time, all the while associating with 408 Durusdinium spp., and did not shuffle to Cladocopium spp. even though they could have. Results 409 from this study and symbiont association data and host population genetics at a micro-geographic 410 scale (see [38]) hint towards local adaptation in P. verweyi.

412 Conclusions

413 Shuffling is not a simple and straightforward way for corals to cope with the effects of climate 414 change, but is in fact a complex process governed by host-symbiont specificity as well as local 415 macro- and micro-environmental conditions. Being flexible [8] is a good strategy, but specificity 416 is also a norm. In other words, a mere increase in temperature above the threshold limit is not 417 enough to invoke shuffling, even if a coral host has the capacity to associate with multiple 418 symbiont partners (see [43]). While it is popular to be optimistic that shuffling or switching 
419 between Symbiodiniaceae genera is a way for corals to survive frequent above-threshold seawater

420 anomalies, we should be cautious, as not all coral species appear to be able to shuffle or switch

421 their associated Symbiodiniaceae genera (e.g. [63]), especially corals that have obligate

422 relationships with a particular Symbiodiniaceae genus. We want to reiterate here that, irrespective

423 of corals' temperature tolerance thresholds in the future, given the fact that we are facing

424 continuous changes in the global climate through carbon emissions, symbiont shuffling might not

425 be sufficient to withstand frequent and prolonged seawater temperature anomalies as it is not a 426 common trait in all coral species.

427

428

\section{Acknowledgements}

430 The authors wish to thank the members of the Coral Lab, Biodiversity Research Center, Academia 431 Sinica (BRCAS; Taipei, Taiwan) for assisting with sampling, field logistics, and molecular 432 analysis. Thanks also to Noah Last of Third Draft Editing for his English language editing. SK was 433 supported by an Academia Sinica postdoctoral fellowship (2012-2014). HST was supported by the 434 Academia Sinica Taiwan International Graduate Program Internship (2016).

435

436

437

438 
439

440

441

442

443

444

445

446

447

448

449

450

451

452

453

454

455

456

457

458

459

460

461

462

463

464

465

466

467

468

469

470

471

472

473

474

475

476

477

478

479

480

481

482

483

484

\section{References}

1.IPCC. 2018 Summary for Policymakers. In: Global warming of $1.5^{\circ} \mathrm{C}$. An IPCC Special Report on the impacts of global warming of $1.5^{\circ} \mathrm{C}$ above pre-industrial levels and related global greenhouse gas emission pathways, in the context of strengthening the global response to the threat of climate change, sustainable development, and efforts to eradicate poverty [V. MassonDelmotte, P. Zhai, H. O. Pörtner, D. Roberts, J. Skea, P. R. Shukla, A. Pirani, W. MoufoumaOkia, C. Péan, R. Pidcock, S. Connors, J. B. R. Matthews, Y. Chen, X. Zhou, M. I. Gomis, E. Lonnoy, T. Maycock, M. Tignor, T. Waterfield (eds.)]. In Press

2. Hughes, T. P., Kerry, J. T., Alvarez_Noriega, A., Alvarez-Romero, J. G., Anderson, K.D., Baird, A. H., Babcock, R. C., Beger, M., Bellwood, D. R., Berkelmans, R., Bridge, T. C., Butler, I. R., Byrne, M., Cantin, N. E., Comeau, S., Conolly, S. R., Cumming, G. S., Dalton, S. J., DiazPulido, G., Eakin, M. C., Figueira, W. F., Gilmour, J. P., Harrison, H. B., Heron, S. F., Hoey, A. S., Hobbs, J-P. A., Hoogenboom, M. O., Kennedy, E. V., Kuo, C-Y., Lough, J. M., Lowe, R. J., Liu, G., Mc Culloch, M. T., Malcolm, H. A., McWilliam, M. J., Pandolfi, J. M., Pears, R. J., Pratchett, M. S., Schoepf, V., Simpson, T., Skirving, W. J., Sommer, B., Torda, G., Wachenfeld, D. R., Willis, B. L., Wilson, S. K. 2017 Global warming and recurrent mass bleaching of corals. NATURE 543, 373-377.

3. Hughes, T. P., Anderson, K. D., Conolly, S. R., Heron, S. F., Kerry, J. T., Mough, J. M., Baird, A. H., Baum, J. K., Beruemn, M. L., Bridge, T. C., Claar, D. C., Eakin, M. C., Gilmour, J. P., Graham, N. A. J., Harrison, H., Hobbs J-P, A., Hoey, A. S., Hoogenboom, M., Lowe, R. J., Mc Culloch, M. T., Pandolfi, J. M., Pratchett, M., Schoepf, V., Torda, G., Wilson, S. K. 2018 Spatial and temporal patterns of mass bleaching of corals in the Anthropocene. Science 359, 80-83.

4. Brown, B. E. 1997 Coral bleaching: causes and consequences. Coral Reefs 16, S129-S138.

5. Marshall, P. A., Baird, A. H. 2000 Bleaching of corals on the Great Barrier Reef: differential susceptibilities among taxa. Coral Reefs. 19, 155-163.

6. Baker, A. C. 2003 Flexibility and specificity in coral-algal symbiosis: diversity, ecology, and biogeography of Symbiodinium. Annual Review of Ecology, Evolution, and Systematics, 661689.

7. Lajeunesse, T. C., Pettay, D. T., Sampayo, E. E., Phongsuwan, N., Brown, B. E., Obura, D. O., Hoegh-Guldberg, O. \& Fitt, W. K. 2010 Long-standing environmental conditions, geographic isolation and host-symbiont specificity influence the relative ecological dominance and genetic diversification of coral endosymbionts in the genus Symbiodinium. Journal of Biogeography 37, 785-800.

8. Silverstein, R. N., Correa, A. M. S. \& Baker, A. C. 2012 Specificity is rarely absolute in coralalgal symbiosis: implications for coral response to climate change. Proceedings of the Royal Society B: Biological Sciences 279, 2609-2618.

9. Lajeunesse, T. C., Parkinson, J. E., Gabrielson, P. W., Jeong, H. J., Reimer, J. D., Voolstra, C. R. \& Santos, S. R. 2018 Systematic Revision of Symbiodiniaceae Highlights the Antiquity and Diversity of Coral Endosymbionts. Current Biology. (doi:10.1016/j.cub.2018.07.008)

10.Weber, M. \& Medina, M. 2012 The role of microalgal symbionts (Symbiodinium) in holobiont physiology. Advances in Botanical Research 64, 119-140.

11.Jones, A. M., Berkelmans, R., Van Oppen, M. J. H., Mieog, J. C. \& Sinclair, W. 2008 A community change in the algal endosymbionts of a scleractinian coral following a natural bleaching event: field evidence of acclimatization. Proceedings of the Royal Society B: Biological Sciences 275, 1359-1365.

12.Sampayo, E. E., Ridgway, T., Bongaerts, P. \& Hoegh-Guldberg, O. 2008 Bleaching 
485

486

487

488

489

490

491

492

493

494

495

496

497

498

499

500

501

502

503

504

505

506

507

508

509

510

511

512

513

514

515

516

517

518

519

520

521

522

523

524

525

526

527

528

529

530

susceptibility and mortality of corals are determined by fine-scale differences in symbiont type. Proceedings of the National Academy of Sciences 105, 10444-10449.

13.Ulstrup, K. E. \& Van Oppen, M. 2003 Geographic and habitat partitioning of genetically distinct zooxanthellae (Symbiodinium) in Acropora corals on the Great Barrier Reef. Molecular Ecology 12, 3477-3484.

14. Fisher, P.L., Malme, M.K., Dove, S. 2012 The effect of temperature stress on coralSymbiodinium associations containing distinct symbiont types. Coral Reefs 31, 473-485.

15. Hume, B. C. C., D'Angelo, C., Smith, E. G., Stevens, J. R., Burt, J., Wiedenmann, J 2015 Symbiodinium thermophilum sp. now., a thermotolerant symbiotic alga prevalant in corals of the world's hottest sea, the Persian/Arabian Gulf. Scientific Reports 5, 8562 doi:10.1038/srep08562

16.Lien, Y.-T., Nakano, Y., Plathong, S., Fukami, H., Wang, J.-T. \& Chen, C. A. C. 2007 Occurrence of the putatively heat-tolerant Symbiodinium phylotype D in high-latitudinal outlying coral communities. Coral Reefs 26, 35-44.

17. Ghavam Mostafavi, P., Fatemi, S. M. R., Shahhosseiny, M. H., Hoegh-Guldberg, O. \& Loh, W. K. W. 2007 Predominance of clade D Symbiodinium in shallow-water reef-building corals off Kish and Larak Islands (Persian Gulf, Iran). Marine Biology 153, 25-34.

18.Oliver, T. A. \& Palumbi, S. R. 2011 Many corals host thermally resistant symbionts in hightemperature habitat. Coral Reefs 30, 241-250.

19.Baker, A. C., Starger, C. J., McClanahan, T. R. \& Glynn, P. W. 2004 Coral reefs: corals' adaptive response to climate change. NATURE 430, 741.

20.Berkelmans, R. \& Van Oppen, M. 2006 The role of zooxanthellae in the thermal tolerance of corals: A 'nugget of hope' for coral reefs in an era of climate change. Proceedings of the Royal Society B: Biological Sciences 273, 2305-2312.

21.Sampayo, E. E., Ridgway, T., Bongaerts, P. \& Hoegh-Guldberg, O. 2008 Bleaching susceptibility and mortality of corals are determined by fine-scale differences in symbiont type. Proceedings of the National Academy of Sciences 105, 10444-10449.

22.Jones, A. M. \& Berkelmans, R. 2008 A community change in the algal endosymbionts of a scleractinian coral following a natural bleaching event: field evidence of acclimatization. Proceedings of the Royal Society B: Biological Sciences 275, 1359-1365

23.Silverstein, R. N., Cunning, R. \& Baker, A. C. 2015 Change in algal symbiont communities after bleaching, not prior heat exposure, increases heat tolerance of reef corals. Global Change Biology 21, 236-249.

24.Cunning, R., Silverstein, R. N. \& Baker, A. C. 2015 Investigating the causes and consequences of symbiont shuffling in a multi-partner reef coral symbiosis under environmental change. Proceedings of the Royal Society B: Biological Sciences 282, 20141725-20141725.

25.Boulotte, N. M., Dalton, S. J., Carroll, A. G., Harrison, P. L., Putnam, H. M., Peplow, L. M. \& van Oppen, M. J. 2016 Exploring the Symbiodinium rare biosphere provides evidence for symbiont switching in reef-building corals. The ISME journal (doi:10.1038/ismej.2016.54)

26. Buddemeier, R. W., Fautin, D. G., Ware, J. R. 1997 Acclimation, adaptation and algal symbiosis in reef-building scleractinian corals. In: Coelenterate biology: proceedings of the sixth international congress of coelenterate biology. Leiden: Nationaal Natuurhistorisch Museum. 3

27.Baker, A. 2001 Ecosystems: reef corals bleach to survive change. Nature 411, 765-766

28 Bay, L.K., Doyle, J., Logan, M., Berkelmans. R. 2016 Recovery from bleaching is mediated by

Peer] reviewing PDF | (2019:09:40918:2:0:NEW 12 Feb 2020) 
531

532

533

534

535

536

537

538

539

540

541

542

543

544

545

546

547

548

549

550

551

552

553

554

555

556

557

558

559

560

561

562

563

564

565

566

567

568

569

570

571

572

573

574

575

576

threshold densities of background thermo-tolerant symbiont types in a reef-building coral. Royal Society open science.3(6):160322. https://doi.org/10.1098/rsos.

29. Goulet T. 2006 Most corals may not change their symbionts. Marine Ecology Progress Series 321, 1-7

30.Hsu, C. M., Keshavmurthy, S., Denis, V. \& Kuo, C. Y. 2012 Temporal and Spatial Variations in Symbiont Communities of Catch Bowl Coral Isopora palifera (Scleractinia: Acroporidae) on Reefs in Kenting National Park, Taiwan. Zoological Studies 51, 1343-1353.

31.Thornhill, D. J., Lajeunesse, T. C., Kemp, D. W., Fitt, W. K. \& Schmidt, G. W. 2006 Multiyear, seasonal genotypic surveys of coral-algal symbioses reveal prevalent stability or postbleaching reversion. Marine Biology 148, 711-722.

32.Thornhill, D. J., Fitt, W. K. \& Schmidt, G. W. 2006 Highly stable symbioses among western Atlantic brooding corals. Coral Reefs 25, 515-519.

33. Palumbi, S. R., Barshis, D. J., Traylor-Knowles, N., Bay, R. A. 2014 Mechanisms of reef coral resistance to future climate change. Science 344, 895-898.

34. Chiou, W.-D., Cheng, L.-Z. \& Ou, H.-C. 1993 Relationship Between the Dispersion of Thermal Effluent and the Tidal Current in the Waters Near the Outlet of the Third Nuclear Power Plant in Southern Taiwan. Journal of Fisheries Society of Taiwan 20, 207-220.

35. Chou, Y., Lin, T. Y., Chen, C. T. A. \& Liu, L. L. 2004 Effects of nuclear power plant thermal effluent on marine sessile invertebrate communities in Southern Taiwan. Journal of Marine Science and Technology 12, 448-452.

36. Fan, K. L. 1991 The Thermal Effluent Problems of Three Nuclear Power Plants in Taiwan. In Oceanography of Asian Marginal Seas, pp. 393-403.

37. Hung, T. C. \& Huang, C. C. 1998 Ecological survey of coastal water adjacent to nuclear power plants in Taiwan. Chemistry and Ecology

38. Keshavmurthy, S., Hsu, C.-M., Kuo, C.-Y., Meng, P.-J., Wang, J.-T. \& Chen, C. A. C. 2012 Symbiont communities and host genetic structure of the brain coral Platygyra verweyi, at the outlet of a nuclear power plant and adjacent areas. Molecular Ecology 21, 4393-4407.

39. Keshavmurthy, S., Meng, P.-J., Wang, J.-T., Kuo, C.-Y., Yang, S.-Y., Hsu, C.-M., Gan, C.-H., Dai, C.-F. \& Chen, C. A. C. 2014 Can resistant coral-Symbiodinium associations enable coral communities to survive climate change? A study of a site exposed to long-term hot water input. PeerJ 2, e327. (doi:10.7717/peerj.327)

40.Keshavmurthy, S., Kuo, C-Y., Huang, Y-Y., Carballo-Bolanos, R., Meng, P-J., Wang, J-T., Chen, C. A. 2019 Coral reef resilience in Taiwan: Lessons from long-term ecological research on the coral reefs of Kenting National Park (Taiwan). Journal of Marine Science and Engineering 388, doi.org/10.3390/jmse7110388.

41.Lee, H. J., Chao, S. Y., Fan, K. L. \& Wang, Y. H. 1997 Tidally induced upwelling in a semienclosed basin: Nan Wan Bay. Journal of Oceanography 53, 467-480.

42.Lee, H.-J., Chao, S.-Y. \& Fan, K.-L. 1999 Flood-ebb disparity of tidally induced recirculation Eddies in a semi-enclosed basin: Nan Wan Bay. Continental Shelf Research 19, 871-890.

43.Kao, K. W., Keshavmurthy, S., Tsao, C. H., Wang, J. T., Chen, C. A. .2018 Repeated and Prolonged Temperature Anomalies Negate Symbiodiniaceae Genera Shuffling in the Coral Platygyra verweyi (Scleractinia; Merulinidae). Zoological Studies 57:55. doi:10.6620/ZS.2018.57- 55.

44.Wellington, G. M., Glynn, P. W., Strong, A. E., Navarrete, S. A., Wieters, E. \& Hubbard, D. 2006 Crisis on coral reefs linked to climate change. Eos Trans. AGU 82, 1-5.

45.Liu, G., Strong, A. E. \& Skirving, W. 2003 Remote sensing of sea surface temperatures during

Peer) reviewing PDF | (2019:09:40918:2:0:NEW 12 Feb 2020) 
577

578

579

580

581

582

583

584

585

586

587

588

589

590

591

592

593

594

595

596

597

598

599

600

601

602

603

604

605

606

607

608

609

610

611

612

613

614

615

616

617

618

619

620

621

622

2002 Barrier Reef coral bleaching. Eos Trans. AGU 84, 137-141.

46.Schoepf, V., Stat, M., Falter, J. L. \& McCulloch, M. T. 2015 Limits to the thermal tolerance of corals adapted to a highly fluctuating, naturally extreme temperature environment. Scientific Reports 5, 17639.

47.Ferrara, G. B., Murgia, B., Parodi, A. M., Valisano, L., Cerrano, C., Palmisano, G., Bavestrello, G. \& Sara, M. 2006 The assessment of DNA from marine organisms via a modified salting-out protocol. Cellular \& molecular biology letters 11, 155-160.

48.Mieog, J., van Oppen, M., Cantin, N. \& Stam, W. 2007 Real-time PCR reveals a high incidence of Symbiodinium clade D at low levels in four scleractinian corals across the Great Barrier Reef: implications for symbiont shuffling. Coral Reefs 26, 449-457.

49.Rasmussen, R. 2001 Quantification on the LightCycler. In Rapid Cycle Real-Time PCR, pp. 21-34. Berlin, Heidelberg: Springer, Berlin, Heidelberg.

50.Tay, Y. C., Noreen, A. M. E., Suharsono, Chou, L. M. \& Todd, P. A. 2014 Genetic connectivity of the broadcast spawning reef coral Platygyra sinensis on impacted reefs, and the description of new microsatellite markers. Coral Reefs 34, 301-311.

51.Miller, K. J. \& Howard, C. G. 2004 Isolation of microsatellites from two species of scleractinian coral. Molecular Ecology Notes 4, 11-13.

52.Yang, S. Y., Fong, W. L., Chow, W. S., Zoological, C. H. 2018 (In press) Development of Novel Polymorphic Microsatellite Markers in Catch Bowl Coral, Isopora palifera (Scleractinia; Acroporidae) Using Next-generation Sequencing.

53. Schuelke, M. 2000 An economic method for the fluorescent labeling of PCR fragments. Nature Biotechnology 18, 233-234.

54.Peakall, R. \& Smouse, P. E. 2012 GenAlEx 6.5: genetic analysis in Excel. Population genetic software for teaching and research--an update. Bioinformatics 28, 2537-2539.

55.Rice, W. R. 1989 Analyzing Tables of Statistical Tests. Evolution 43, 223-225.

56.Excoffier, L., resources, H. L. M. E.2010 In press. Arlequin suite ver 3.5: a new series of programs to perform population genetics analyses under Linux and Windows. Molecular Ecology Resources 10, 564-567.

57.Pritchard, J. K., Stephens, M., Donnelly, P. 2000 Inference of population structure using multilocus genotype data. Genetics 155, 945-959.

58.R Core Team (2014). R: A language and environment for statistical computing. R Foundation for Statistical Computing, Vienna, Austria. URL http://www.R-project.org/.

59.Bay, L. K., Doyle, J., Logan, M. \& Berkelmans, R. 2016 Recovery from bleaching is mediated by threshold densities of background thermo-tolerant symbiont types in a reef-building coral. Royal Society Open Science 3, 160322.

60. Lee, J.L., Jeong, H. J., Jang, S. H., Lee, S. Y., Kang, N. S., Lee, K. H., Kim, S. K., Wham, D. C., LaJeunesse, T. C. 2016 Most low-abundance "Background" Symbiodinium spp. are transitory and have minimal functional significance for symbiotic corals. Microb Ecol 71, 771783.

61.Howells, E. J., Abrego, D., Meyer, E., Kirk, N. L. \& Burt, J. A. 2016 Host adaptation and unexpected symbiont partners enable reef-building corals to tolerate extreme temperatures. Global Change Biology 22, 2702-2714.

62. Obura, D. O. 2005 Resilience and climate change: Lessons from coral reefs and bleaching in the Western Indian Ocean. Estuarine Coastal And Shelf Science 63, 353-372.

63. Coffroth, M. A., Poland, D. M., Petrou, E. L., Brazeau, D. A. \& Holmberg, J. C. 2010 Environmental Symbiont Acquisition May Not Be the Solution to Warming Seas for Reef-

Peer] reviewing PDF | (2019:09:40918:2:0:NEW 12 Feb 2020) 
623 Building Corals. PLoS ONE 5, e13258.

624

625

626

627

628

629 


\section{$630 \quad$ Figures}

631

632

633

634

635

636

637

638

639

640

641

642

643

644

645

646

647

648

649

650

651

652
Figure 1. Map showing the reciprocal transplant experiment locations in the Kenting National Park, Taiwan. NPP-OL - Nuclear Power Plant Outlet, NPP-IL - Nuclear Power Plant Inlet, and WLT - Wanlitung.

Figure 2. Seawater temperature (weekly average) trend (A) and DHW (B) at three locations: Red line - NPP-OL, Black line - WLT, and Blue line - NPP-IL, in 2014 and 2015. Typhoons in 2015 are represented as arrows.

Figure 3. Symbiodiniaceae genera trends (A) in five native cores of $P$. verweyi during the 2014 transplantation experiment and (B) in 30 native cores of $P$. verweyi during the 2015 transplantation experiment. Each colour block represents one core sampled from one individual colony. In the case of NPP-IL, no samples were collected after July 2015. X = the cores were dead.

Figure 4. Symbiodiniaceae genera trends in bi-monthly sampling of tagged mother colonies at each location in 2014-2016. Each colour block represents one core sampled from one individual colony. In the case of NPP-IL, there were no samples after November 2015.

Figure 5. Bar plot of STRUCTURE. Bayesian clustering analysis for eight loci genotypes among the NPP-OL and WLT $P$. verweyi populations. This bar plot assumed the number of population $\mathrm{K}=2.1,000,000 \mathrm{MCMC}$ runs. 


\section{Table $\mathbf{1}$ (on next page)}

Characteristics of microsatellite loci

Characteristics of eight microsatellite loci for 60 colonies of $P$. verweyicollected at NPP-OL and Wanlitung. 
1 Table 1. Characteristics of eight microsatellite loci for 60 colonies of $P$. verweyi collected at NPP2 OL and Wanlitung.

3

4

\begin{tabular}{|c|c|c|c|c|c|c|}
\hline locus & Primers sequences & repeats & $\begin{array}{l}\text { Size of } \\
\text { alleles }\end{array}$ & $\begin{array}{l}\text { Tm } \\
\left({ }^{\circ} \mathrm{C}\right)\end{array}$ & $\begin{array}{l}\text { No. } \\
\text { alleles }\end{array}$ & $\mathbf{H}_{\mathrm{E}}$ \\
\hline PV9 & $\begin{array}{l}\text { F:†CAACTTAAATGGTATCATCGT } \\
\text { G } \\
\text { R: GTGCCCTATTTTATGTGACAA }\end{array}$ & $(\mathrm{AG})_{26}$ & $140-168$ & 50 & 9 & 0.85 \\
\hline PV19 & $\begin{array}{l}\text { F:†TAGTCAGTGGCATCTGAGAGT } \\
\text { R: CTCATTTCCTCCTAAGCTTTC }\end{array}$ & $(\mathrm{TG})_{30}$ & $161-197$ & 53 & 16 & 0.83 \\
\hline PV22 & $\begin{array}{l}\text { F:†TCACTTGCTATAACCTTCTCCT } \\
\text { R:TCCACCTCTCCAACTAGTTATC }\end{array}$ & $(\mathrm{TG})_{12}$ & $140-164$ & 50 & 10 & 0.86 \\
\hline PV56 & $\begin{array}{l}\text { F:†TTGACTCGTCAATCACCTATC } \\
\text { R: GCTAGCACTGATCAAACGAT }\end{array}$ & $(\mathrm{TC})_{14}$ & 144-166 & 50 & 6 & 0.75 \\
\hline PV57 & $\begin{array}{l}\text { F:†ACAGACAGAGACAGACAGAA } \\
\text { CA } \\
\text { R: CAGTTCACCTGTCCATTTG }\end{array}$ & $(\mathrm{TC})_{14}$ & $103-119$ & 50 & 6 & 0.60 \\
\hline $\begin{array}{l}\text { Plsi4.0 } \\
2\end{array}$ & $\begin{array}{l}\text { F:†ACAATTCGGATATGTAGC } \\
\text { R:GTTTCTTTGGTTTGGTTTGTTCT } \\
\text { C }\end{array}$ & $(\mathrm{AAAC})_{11}$ & $136-170$ & 50 & 14 & 0.85 \\
\hline $\begin{array}{l}\text { Plsi4.2 } \\
4\end{array}$ & $\begin{array}{l}\text { F:†TTATCTTGGTTCAGACAGACA } \\
\text { G } \\
\text { R:GTTTGACAACTCTAATGAAGGT } \\
\text { CAG }\end{array}$ & $(\mathrm{ACAG})_{10}$ & $126-158$ & 59 & 9 & 0.77 \\
\hline PD31 & $\begin{array}{l}\text { F:†GACAAGTAATGTGTAAATCGT } \\
\text { TGTCC } \\
\text { R:†CTGTTAGAGTATCATGTCCTG } \\
\text { AAGC }\end{array}$ & $(\mathrm{CCAT}) 7$ & 156 & 56 & 7 & 0.54 \\
\hline
\end{tabular}

$5 \dagger$ primer attached M13 (-21) tail (5’- TGT AAA ACG ACG GCC AGT -3’) (18 bp)

6

7 


\section{Figure 1}

Map showing the reciprocal transplant experiment locations in the Kenting National Park, Taiwan.

Map showing the reciprocal transplant experiment locations in the Kenting National Park, Taiwan. NPP-OL - Nuclear Power Plant Outlet, NPP-IL - Nuclear Power Plant Inlet and WLTWanlitung. 


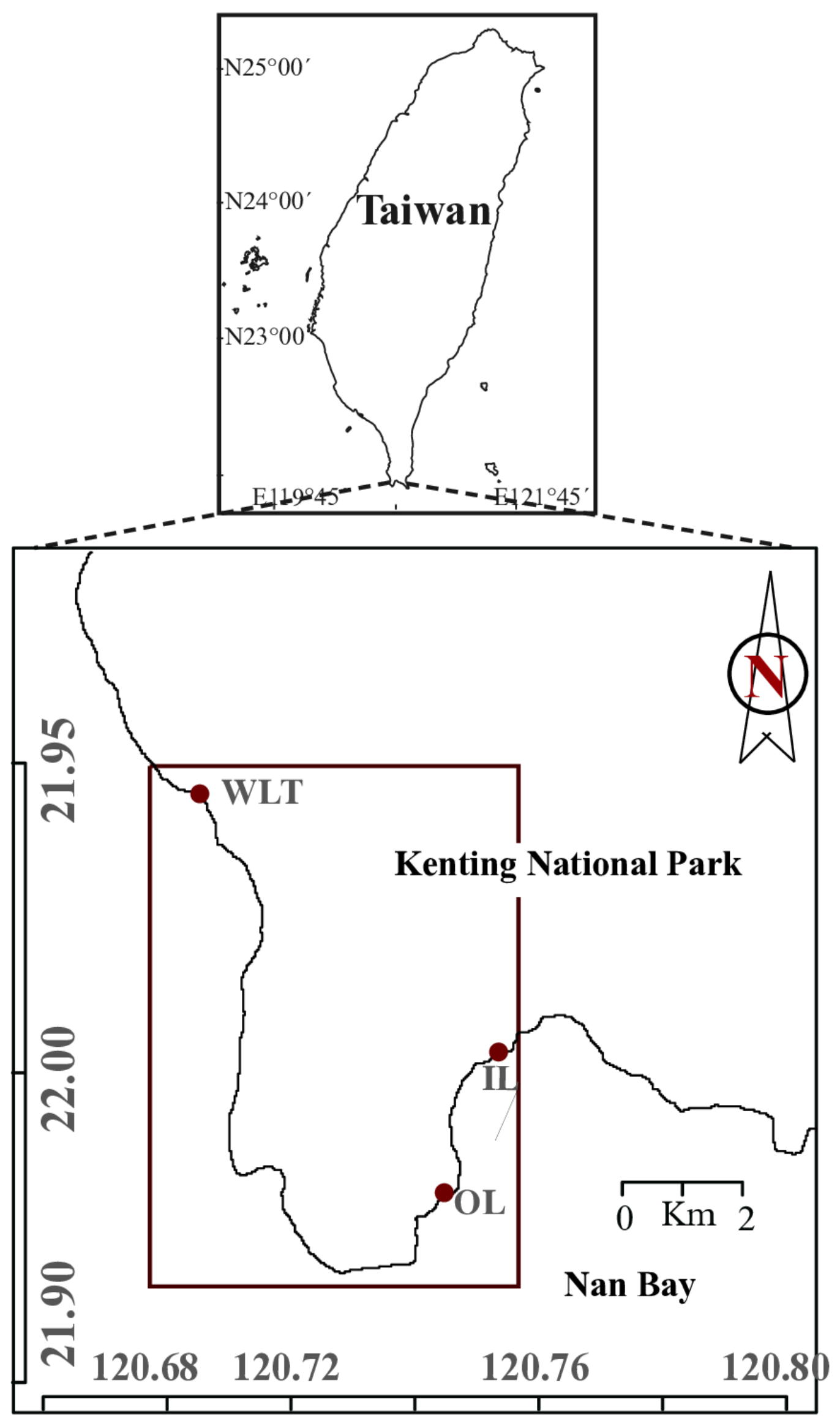

Peer] reviewing PDF | (2019:09:40918:2:0:NEW 12 Feb 2020) 
Figure 2

Seawater temperature (weekly average) trend

Seawater temperature (weekly average) trend (A) and DHW (B) at three locations: Red line NPP-OL, Black line -WLT and Blue line - NPP-IL, in 2014 and 2015. Typhoons in 2015 are represented as arrows

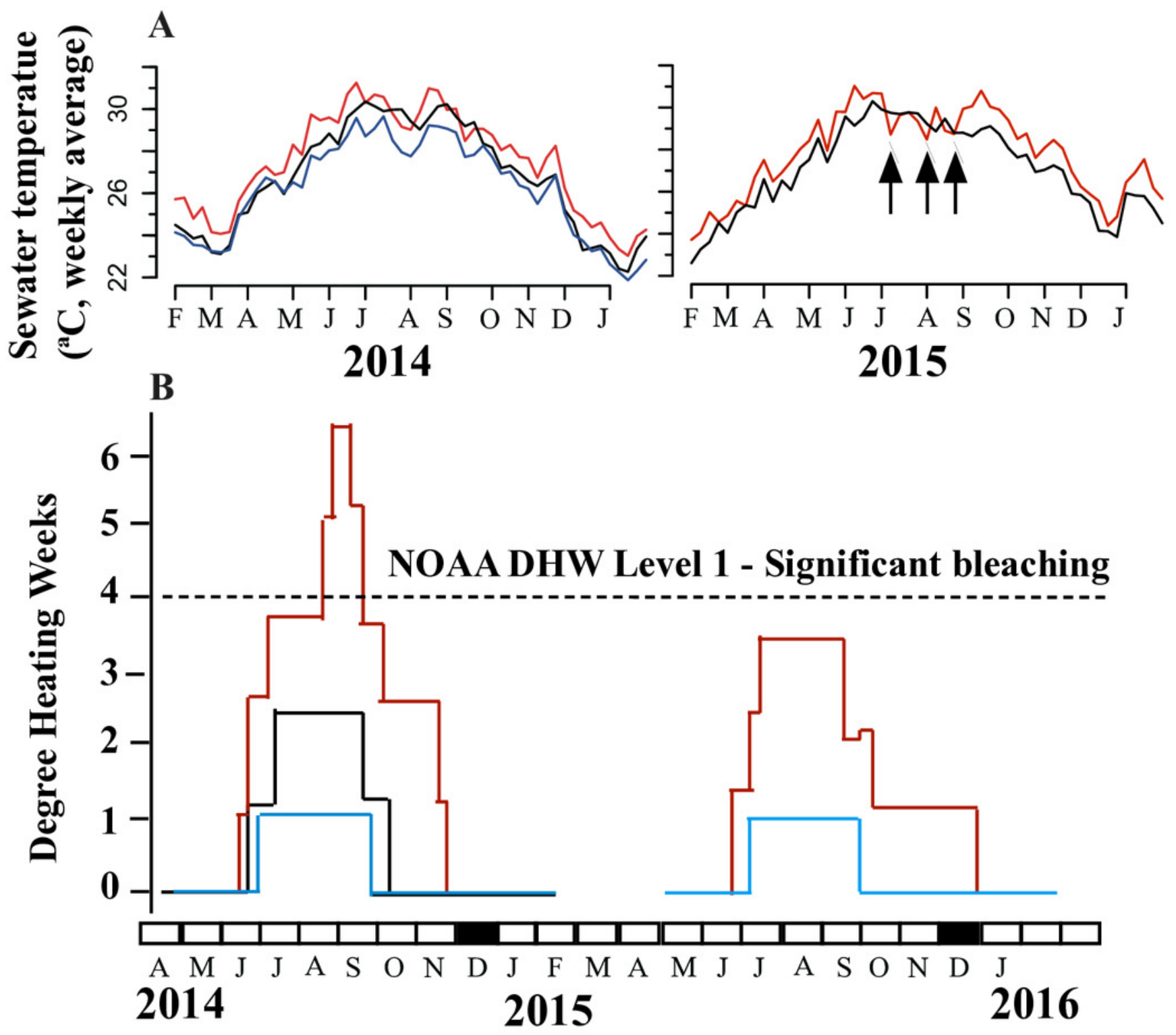




\section{Figure 3}

Symbiodiniaceae genera trends

Symbiodiniaceae genera trends (A) in five native cores of $P$. verweyi during the 2014 transplantation experiment and (B) in 30 native cores of $P$. verweyi during the 2015 transplantation experiment. Each colour block represents one core sampled from one individual colony. In the case of NPP-IL, no samples were collected after July 2015. X = the cores were dead.
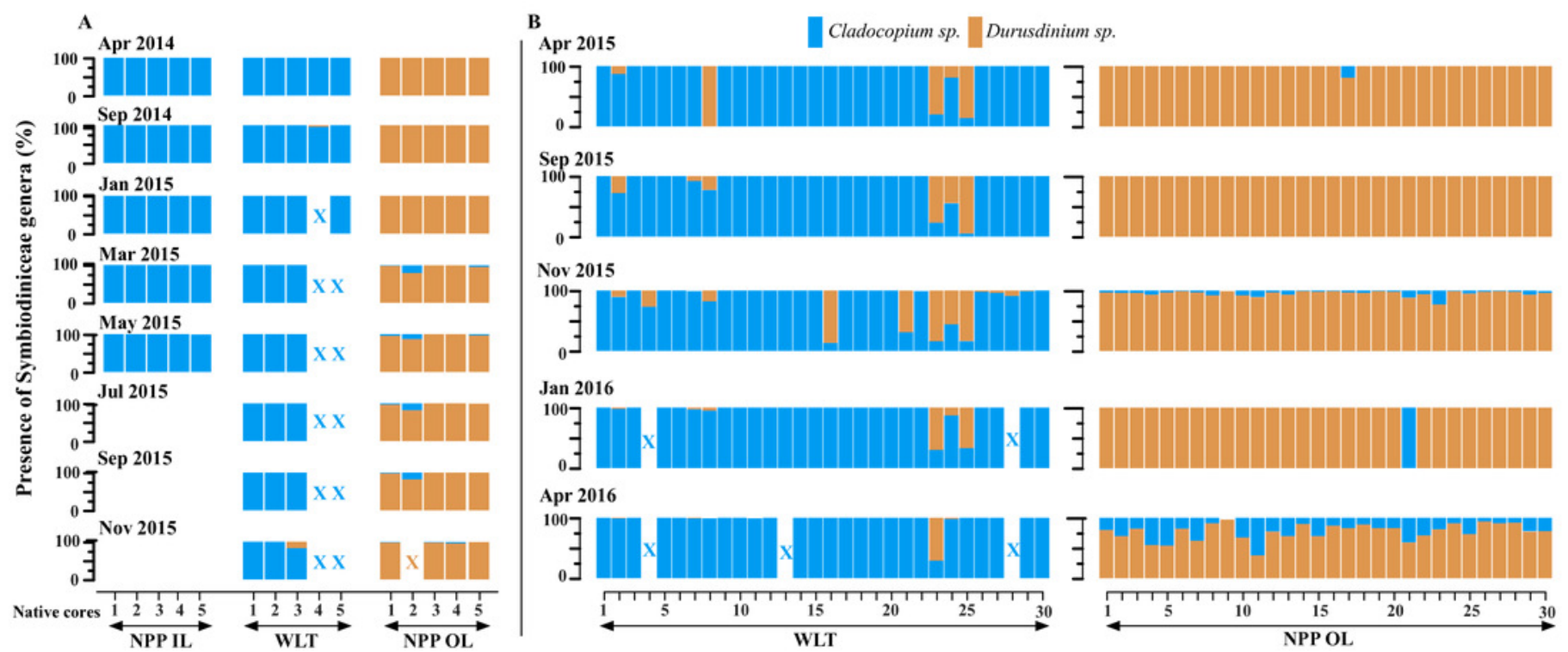
Figure 4

Symbiodiniaceae genera trends

Symbiodiniaceae genera trends in bi-monthly sampling of tagged mother colonies at each location between 2014-2016. Each colour block represents one core sampled from one individual colony. In the case of NPP-IL, there were no samples after November 2015. 


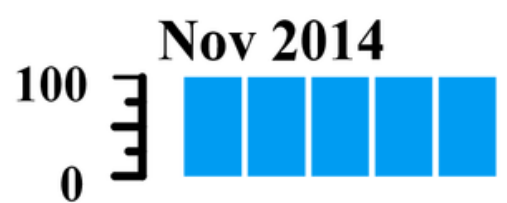

\section{Cladocopium sp. Durusdinium sp.}

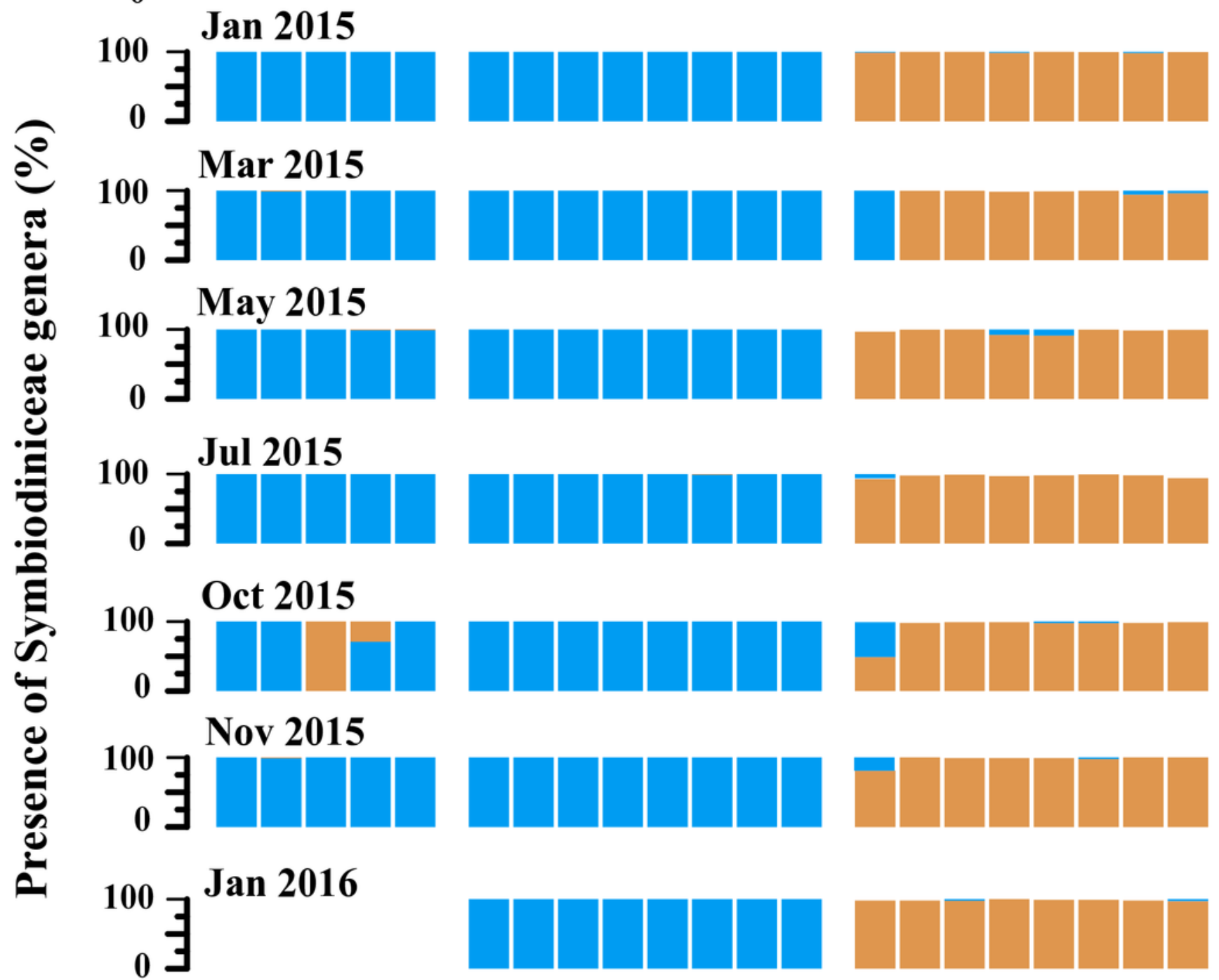

$$
100 \exists^{\text {Apr } 2016}
$$
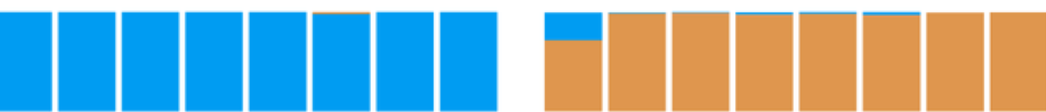


\section{Figure 5}

\section{Bar plot of STRUCTURE}

Bar plot of STRUCTURE. Bayesian clustering analysis for eight loci genotypes among the NPPOL and WLT $P$. verweyi populations. This bar plot assumed the number of population $\mathrm{K}=2$. $1,000,000$ times MCMC runs.

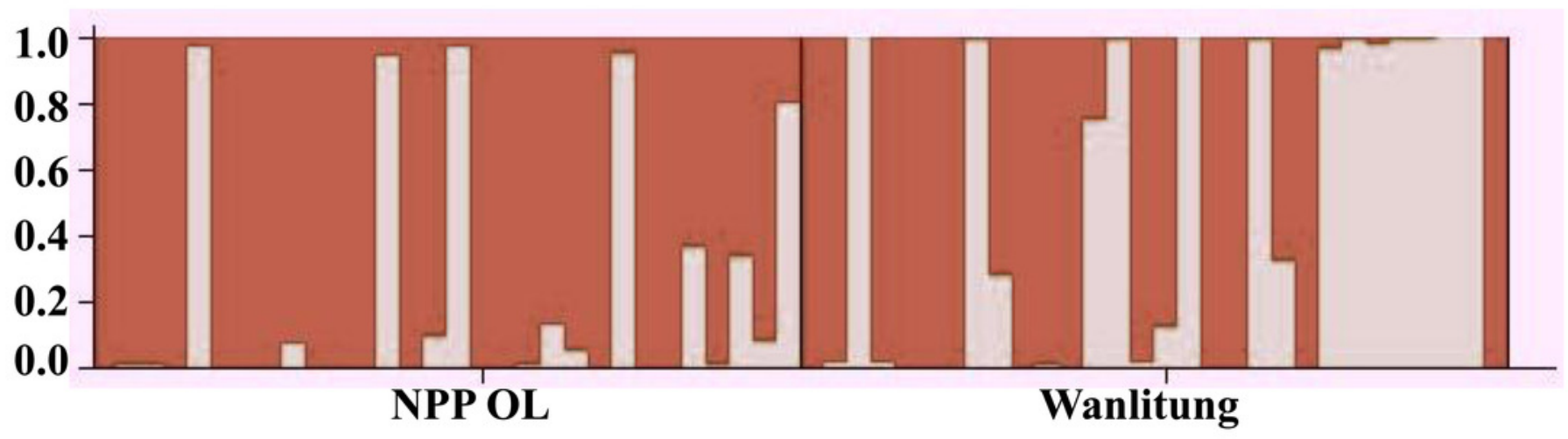

